\title{
Sustainable in Action: From Intention to Environmentally Friendly Practices in Makerspaces Based on the Theory of Reasoned Action
}

\author{
Antje Klemichen, Ina Peters* and Rainer Stark \\ Department of Industrial Information Technology, Institute for Machine Tools and Factory, Technische Universität Berlin, \\ Berlin, Germany
}

OPEN ACCESS

Edited by:

Tomohiko Sakao,

Linköping University, Sweden

Reviewed by:

Heather Moorefield-Lang,

University of North Carolina at

Greensboro, United States

Michael J. Tagler,

Ball State University, United States

Manuel Moritz,

Helmut Schmidt University, Germany

${ }^{*}$ Correspondence:

Ina Peters

ina.roeder@tu-berlin.de

Specialty section:

This article was submitted to

Sustainable Organizations,

a section of the journal

Frontiers in Sustainability

Received: 02 March 2021

Accepted: 26 April 2021

Published: 18 February 2022

Citation:

Klemichen A, Peters I and Stark $R$ (2022) Sustainable in Action: From Intention to Environmentally Friendly Practices in Makerspaces Based on the Theory of Reasoned Action.

Front. Sustain. 2:675333.

doi: 10.3389/frsus.2021.675333
The steady growth of makerspaces to decentralized production enables access to new and previously unknown technologies for diverse users and thus equally promotes the social-ecological change in society. First, such facilities offer a physical space where ideas and innovations can be realized as prototypes or in small series. Secondly, they are also considered social spaces where people come together, exchange ideas, work collaboratively, and learn. The acquired knowledge is carried home and into peer groups outside the makerspaces. Therefore, in theory the maker scene has great potential for sustainable development especially in the educational and awareness raising context. However, there is a strong heterogeneity among makers not only in their intentions to use such places, but also in their educational background and experience in product development as well as in dealing with technology in general. It has been shown that makers certainly have an awareness of the need for sustainable development, however, this is not reflected in their actual making practices. Rather, makerspaces are characterized by high consumption of resources. A fundamental aspect here is the self-image of makers, in which sustainability plays a subordinate role. It is thus important to support individual production, which is associated with increasing consumption of resources in the early design phase, and to consider environmental aspects-even before 3D printers and laser cutters are switched on. In order to meet knowledge gaps and lack of motivation toward sustainable product creation in makerspaces, the ecoMaker project developed a theoretical framework that builds the bridge from knowledge to action. From this a concept for practical implementation is suggested that combines. Engineering processes and sustainability knowledge with established methods from the start-up scene transferred into tools and methods for the maker scene based on maker requirements. Those tools and methods are to be visibly installed at various places in the makerspace and target different stages of project ideas to help makers develop greener products and raise awareness of the makerspace as a place that promotes sustainable development. The elements have been co-developed with makers, applied in makerspaces and are freely available according to the open-source approach.

Keywords: sustainable product development, makerspace, education, attitude-behavior, reasoned action approach, self-identity, ecodesign 


\section{INTRODUCTION}

The commonly entitled "maker movement" is said to have the potential of an industrial revolution, which is given additional momentum by the rapidly growing worldwide network for desktop machine tools (Anderson, 2012). People are gaining access to means of production and are thus enabled to produce goods for their own needs. These "makers" are increasingly moving and networking in the digital space and are inspired by countless example products on maker platforms. Production is organized in a collaborative, decentralized manner at various locations such as repair cafés, fab labs, and other forms of makerspaces. These places are characterized by their public accessibility, their associated shared network and the support of individual production through their collective knowledge, skills, and equipment such as 3D printers, laser cutters, soldering stations, etc. They are places of collective learning and often strive toward open knowledge and social commitments such as empowerment of marginalized groups (Unterfrauner et al., 2020).

Makerspaces are assumed to have the potential to contribute to environmental sustainability by raising awareness for sustainable product development and sustainable products (Unterfrauner et al., 2019). However, studies show that although values regarding environmental sustainability are widespread among makers, they find little application in maker practice (Kohtala and Sampsa, 2015; Klemichen and Roeder, 2018). In this article, we identify causes for the lack of practical implementation based on literature review as well as own data. Employing social and environmental psychological theories, we develop a theoretical framework to overcome this "attitude-behavior-gap" (Kohtala, 2016) specifically for the setting of makerspaces, and also present a concept for practical implementation of which several elements have been prototypically tested in two Berlin makerspaces under real conditions. However, the final evaluation of the overall concept had to be postponed due to the shutdown of makerspaces following the pandemic regulations of 2020/2021 and remains to be conducted.

To explore how the topic of eco-friendliness can be integrated into makerspaces' learning environments, we will first look at makerspaces' and makers' characteristics in general as well as regarding attitudes and behavior targeting environmental sustainability, thus narrowing down promising settings. Subsequently we examine social and environmental psychological theories that deal with preconditions for environmentally friendly behavior, followed by an overview of principles of sustainable product development. From all this we derive our theoretical framework before we present the prototypical realization of different parts of the ecoMaker concept for promoting environmentally friendly practices in makerspaces.

\section{SCIENTIFIC STARTING POINTS: MAKERSPACES, MAKERS, AND BEHAVIORAL DECISION MAKING}

With the rapidly growing number of makerspaces popping up all over the world, the hybrid role of the "prosumer" (Toffler, 1980) has gained momentum within the economic field. The term refers to people who are producers and consumers in one. From this new role the assumption is derived that making is particularly suited to create awareness among makers of issues such as renewable materials, resource consumption and product lifespan, that is sustainable product development (e.g., Millard et al., 2017; Schoneboom, 2018). People come together in makerspaces to share ideas, tools and knowledge and transform them into artifacts. There they find both physical spaces, equipped with more or less high-tech tools, and social spaces in which collaboration and exchange take place on a personal level between individual thinkers and hobbyists as well as an institutional level e.g., between makerspaces and companies. The basic idea of such spaces is to allow an uncomplicated public access to expensive machine tools as they were previously only used in industry by sharing. However, sharing as a business model in this context is not limited to machines and tools, but also to knowledge and skills (Toombs et al., 2015). Collaboration is the standard way of doing things in makerspaces although often informally and spontaneously. However, makerspaces follow different business forms, business models, and modes of operation, focusing e.g., on innovation or empowerment. The specific public that is granted access to machinery and networks might differ from tinkerers to professional designers. Thus, the communities that form around makerspaces are shaped accordingly. Community in this context should not necessarily be understood in the classical sociological sense of a tightly woven social network, but refers to a connection that can be independent of spatial proximity or even an active social relationship and is rather established through shared practices (Grabher and Ibert, 2014). But regardless of the level of expertise and professionalization all those communities are bodies of collaborative learning and collective knowledge (Zamiri and Camarinha-Matos, 2019). Makerspaces are therefore, to a large extent places of learning and usually indeed see themselves as such (Sheridan et al., 2014; Unterfrauner et al., 2020). Continuous exchange among makers forms the indispensable basis for those learning but also joint creativity processes. This is taken up in the design of the places that often promotes spontaneous collaborative work (Osorio et al., 2019), with shared workstations arranged as isles, machinery placed well-visibly in open spaces and a just as open area that serves as a kitchenette and social exchange point. While such values of social sustainability are rather obvious in many makerspaces, the environmental values are far less explicitly visible. Building and maintaining the community is essential to the success of a makerspace. While new members are recruited with access to machines and tools, they are retained through successful integration into the makerspace community. Makerspace operators and established community members spend a lot of time and energy creating an atmosphere of belonging among their members (Toombs et al., 2015). The "tactics of care" applied for this purpose result in a maker culture that emphasizes an "ethos of empowerment." This includes ideals of independence and individualism, but also a role model of the maker as interdependent community member.

While they all see themselves as "makers," the members of different communities can pursue very different goals. Members can be students that use makerspace as part of their studies, but 
also DIY hobbyists or self-employed people and start-ups with economic interests. To many makers the process of creating the product is almost as important as the product itself. They enjoy the process and see the path to the finished product as a learning opportunity. For the self-employed and startups, makerspaces provide access to rapid prototyping tools, which can be existential for their business. In addition, such spaces provide them with a local network with access to potential partners, subcontractors and users of their products. Another reason for the economicoriented use are business models based on highly individualized products or small batch production for a local need. However, makers and their communities differ not only in terms of their goals, but also in terms of their values and beliefs, especially with regard to the relationship of makerspaces to the classical market but also regarding the purpose of makerspaces. Unterfrauner et al. (2020) differentiate three cultural fields (openness, market, making) to which they allocate five types of makers according to their values: (1) "Utopian makers" clearly distance themselves from the values of the market, advocate openness and are driven by an enthusiasm for the process of making itself. (2) "Pragmatic makers" do not necessarily see openness and the traditional market as opposites, but consider there to be potential for further models. (3) "Social Makers" stand for social values, identify strongly with their community, and see making and openness as opportunities for participation and empowerment also in the economic field. Their projects often target environmental protection issues. (4) "Making to market makers" is about the marketability of products from makerspaces, contrary to the idea of openness. The membership in the makerspace serves commercial or career goals. (5) "Mainstream makers" try to make use of openness as competitive advantage under the condition that it relies on a strong community. This type is very common and integrates makers from all three cultural fields. Obviously type 3 "Social makers" are most likely to adapt sustainability criteria in their making strategies even if this would add to the costs. For type 4 "Making to market makers" on the other hand eco-friendly product development is likely to be neglected as long as it does not offer an economical advantage. All other types can be seen as potentially open to ideas of environmental sustainability, depending on the single case. Therefore, the assumption that makers are in principle pro-ecological and drivers for sustainable product development as promoted by media regularly (Hartmann et al., 2016), must be rejected as unjustified simplification.

In the scientific field the effect of makerspaces and making on environmental sustainability is indeed controversially discussed (Kohtala, 2016). On the one hand rebound effects are often observed in makerspaces (Petschow et al., 2014). In particular, $3 \mathrm{D}$ printing with its low material and operating costs leads to a strong increase in plastic waste due to misprints and the lack of possibility to disassemble printed products, e.g., to replace only individual parts. The common trial-and-error approach to product development in makerspaces (Klemichen and Roeder, 2018) as well as the frequent practice of making for the fascination of making rather than the need of artifacts contribute to resource load. In addition, it is argued that a lot of projects in makerspaces tackle challenges of environmental sustainability
TABLE 1 | Environmental impacts of makerspaces, adapted from Kohtala and Sampsa (2015).

\begin{tabular}{|c|c|c|c|c|c|}
\hline Aspects & 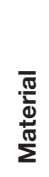 & 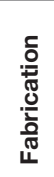 & 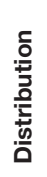 & 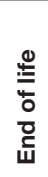 & 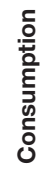 \\
\hline \multicolumn{6}{|l|}{ ( $\uparrow$ positive impacts } \\
\hline \multicolumn{6}{|l|}{$(\downarrow)$ negative impacts } \\
\hline \multicolumn{6}{|l|}{$(\leftrightarrow)$ unstudied } \\
\hline \multicolumn{6}{|l|}{ Current practices } \\
\hline Biodegradability & $\uparrow$ & & & & \\
\hline Durability & $\uparrow$ & $\uparrow$ & & & \\
\hline Renewable sources & $\leftrightarrow$ & $\leftrightarrow$ & & & \\
\hline Toxicity & $\downarrow$ & & & & \\
\hline Packaging & $\uparrow$ & & $\uparrow$ & & \\
\hline Emissions & & $\uparrow$ & & & $\leftrightarrow$ \\
\hline Energy & & $\downarrow$ & & & \\
\hline Dematerialisation & $\leftrightarrow$ & & & & $\leftrightarrow$ \\
\hline \multicolumn{6}{|l|}{ Reparability } \\
\hline Recyclability & $\uparrow$ & & & $\downarrow$ & \\
\hline
\end{tabular}

and that there is a strong identification with practices of repair, recycle and upcycle in the maker scene (Unterfrauner et al., 2019). Kohtala and Sampsa (2015) have mapped positive and negative impacts in makerspaces as summarized in Table $\mathbf{1 .}$

citetbib15 also describes the contradiction that makers from the Global North experience when trying to implement ideologically driven product ideas within the "gentrified and limiting everyday routine" in makerspaces. From this, she derives the concept of an "attitude-behavior-gap" of makers when it comes to environmental sustainability. However, like Unterfrauner et al. (2020), Kohtala (2016) also emphasize that there are numerous subcultures in the maker scene, some of which differ greatly in terms of their sustainability orientation and also knowledge. While existing knowledge about environmentally friendly materials, manufacturing processes and business models is shared among makers, they often lack detailed information about the environmental impact of materials or products to share and assess the greenness of their products (Unterfrauner et al., 2019). However, makers are usually not too interested in determining the environmental friendliness of their products. In general, it can be said that the focus in makerspaces regarding environmental sustainability is rather, if at all, producing artifacts that help meet environmental challenges than implementing sustainability measures in the process of making (ibid.) and even that only applies to certain maker types.

In order to develop mechanisms that promote environmental sustainability in makerspaces and among makers, we must first understand what factors actually determine human behavior. The idea that actions result directly from a person's values and attitudes, much the less from simple awareness, has been outdated since Wicker's (1969) attempts to predict actions 
based on attitudes in the 1960s. Since then, it is primarily the continuously developed and widely tested Theory of Reasoned Action (Fishbein and Ajzen, 1975), its successor Theory of Planned Behavior (Ajzen, 1988) and, resulting from it, the Reasoned Action Approach (Fishbein and Ajzen, 2010), that has been found useful when it comes to fathoming the variables influencing human decision behavior. According to Fishbein and Ajzen (2010), human behavior depends on at least three factors as shown in Figure 1: (1) behavioral beliefs, (2) normative beliefs, and (3) control beliefs. Behavioral beliefs describe the consequences that someone expects to result from a certain action. Normative beliefs refer to the assumed expectations of others regarding one's own behavior. Control beliefs revolve around expected barriers and facilitators that might affect the feasibility of a behavior. If a person expects the consequences of a behavior to be mostly positive, his or her peers or role models endorse the behavior or even practice it themselves, and he or she expects more support than obstacles in practicing it, he or she will develop a positive attitude toward the behavior, and is likely to take it on. Thus, the first factor relates to a win-loss consideration, the second to social pressure and social norms, and the third to self-efficacy assumptions. It is only from the weighing of these factors that a person develops the intention to act or not to act and will behave accordingly as far as external constraints allow it. Assumptions or beliefs are thus the basis for intentions and ultimately action. Beliefs, in turn, are always influenced by cultural and subcultural socialization processes as well as by a person's personal traits as shown in Figure 2.

Social psychology is continuously searching for additional factors that influence behavioral decisions, many of which have been incorporated into the approach because of their proven statistical significance. One construct whose significance has been proven many times, especially in studies on environmentally conscious behavior (Chen, 2016, 2020), but which has not yet found its way into the Reasoned Action Approach due to methodological disagreements, is self-identity (Snippe et al., 2021). The concept of self-identity is based on the constructivist assumption that people perceive the world in specific ways, depending on the representations of it they have created in their minds. People construct images of everything that surrounds them, mostly influenced by the expressed representations of other people from their environment as well as by their own experiences. Part of this mental image of the world in a person's mind is the image of himself or herself. This image is called self-identity in psychology. This basically means that we attribute certain characteristics to ourselves. Self-identity, in itself, is composed of a variety of such attributed characteristics. Accordingly, our perceived self is multifaceted. Which facet is dominant in our self-attribution at a given moment depends on our role in the respective social setting (Stryker and Serpe, 1982). Therefore, self-identity does not exist by itself but is always also connected to the social surrounding. Mental constructs can furthermore be activated to a certain degree by external stimuli (Bargh et al., 2010), e.g., nudging a person to interpret information in preselected ways by offering other information beforehand that directs the persons's thoughts in the targeted direction. This is called priming. Applied to self-identity this could mean that certain identity aspects could be raised by reminding a person of his or her corresponding role in which this very self-identity becomes salient. For example, if a person is reminded of his or her role within the local makerspace's maker community and that person associates this role with values of market independence, a subsequent offer to purchase cheap materials of a market leader might be recognized as identityincongruent (Oyserman, 2015) and opposed to the communities' social norms. This might trigger that person to reject the offer in favor of buying from a smaller yet probably more costly supplier. If the same person had been reminded of his or her role as low earner and breadwinner of a family instead, his or her choice might have been different. Therefore, the question which self-identities are active in a maker when making decisions is important.

The social setting with its social norms, associated roles and values thus has a determining effect on people's selfidentity (Turner et al., 1987) and their behavioral decisions. Memberships in explicit social groups and categories have a particularly high potential to lead to such effects (Terry et al., 1999), since membership is always constructed in distinction to non-membership and images exist of a prototypical member against which one can measure oneself or to which one can adapt. Makerspace communities are such explicit social groups. Therefore, if changes in makers' behavior are targeted, it seems a good idea to take the social setting of the makerspace into consideration, namely its community, the community's values, and its role models.

But what does environmental sustainability mean in the context of makerspaces? According to many authors (e.g., Prendeville et al., 2017; Unterfrauner et al., 2019), the activities of makerspaces are already tangential to many principles of the circular economy, e.g., by extending product life through repair and sharing resources by collaborative commons. In addition, the aspect of education can be perceived as a tentative move toward a general participation in the sharing industry (Newlands et al., 2018). In contrast to engineers concentrating primarily on the specific product properties and functionalities (Halstenberg et al., 2019) and following strictly pre-defined processes, designers develop concepts implemented in the approach of eco or sustainable design (Sherwin, 2004) to improve the environmental performance of products. They are supported by a broader framework integrating qualitative techniques such as checklists and superior guidelines (e.g., MET Matrix, Ten Golden Rules, eco Design checklist) as well as quantitative techniques considering product life cycle assessments (Luttrop and Lagerstedt, 2006; Bovea and PérezBelis, 2012). Furthermore, Rossi et al. (2016) incorporate overarching approaches such as Design for $\mathrm{X}$ (e.g., Design for disassembly or recycling) as well as computer-aided design integrated tools. In particular, the methods and methodologies mentioned above can be understood as general-purpose tools that do not require a high level of expertise and therefore do not contradict the paradigm of making, that is to realize projects low-cost and fast (Roeder and Klemichen, 2019). Rather, it considers the fact of the in-depth makers knowledge and project motivation heterogeneity, especially on rapid prototyping and experimentation of designs especially for profitorientated start-ups that have to "anticipate and prepare for 


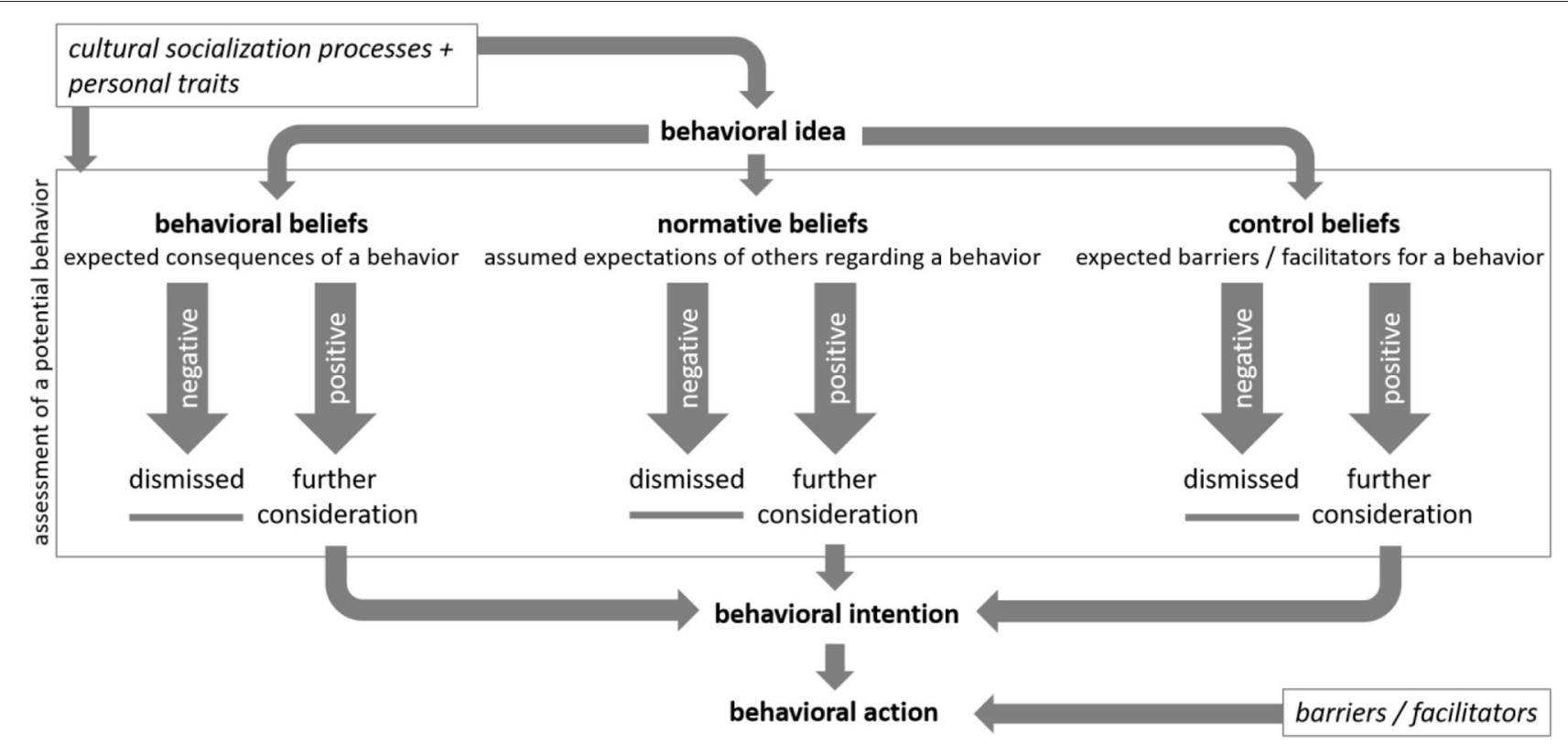

FIGURE 1 | Behavioral decision making as seen by Fishbein and Ajzen's (Fishbein and Ajzen, 2010) reasoned action approach.

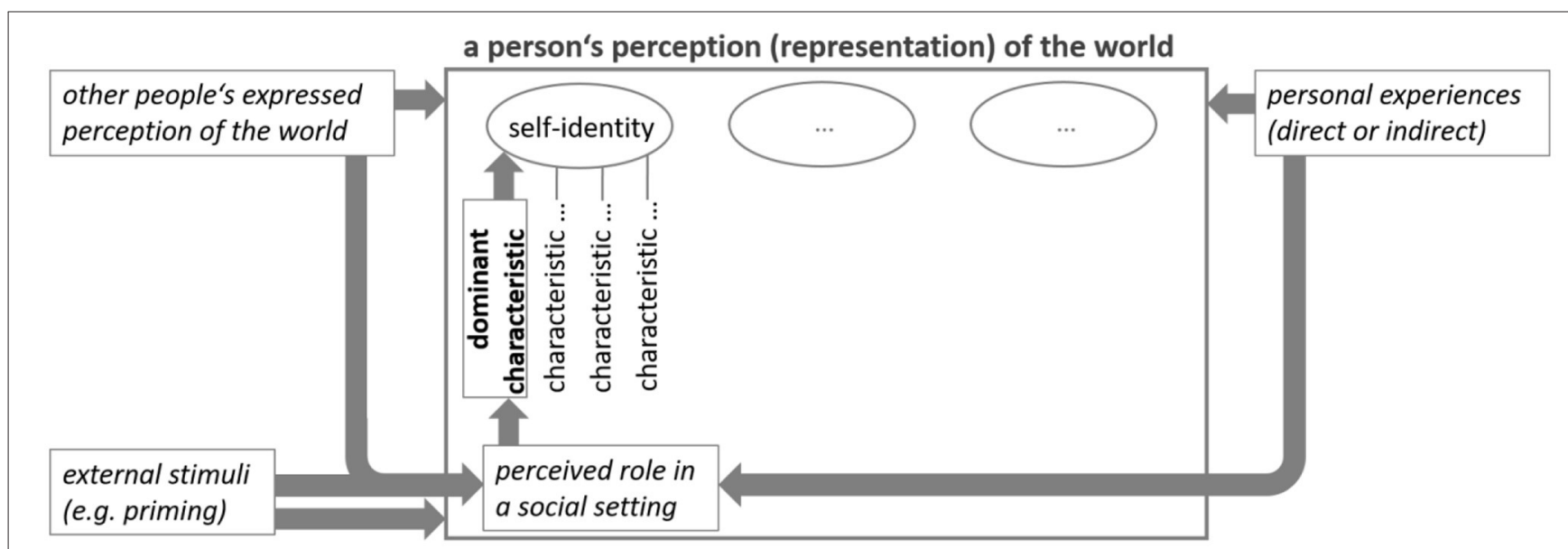

FIGURE 2 | Cultural socialization processes and personal traits that influence behavior decision making.

alternative economy" (Andrews, 2015). In this context the methodology of Design Thinking (DT) has been established within the designer community and does not represent a strict set of rules, but provides a comprehensive framework of analytical and creative tools and methods (Liedtka, 2015). It is supplemented with aspects for sustainable product and business development e.g., the integration of a multiple stakeholder perspective (Andrews, 2015; Geissdoerfer et al., 2016; Buhl et al., 2019) and has its focus on the consumer in product development. In addition to the technical design of products, both production and consumption characteristics influence the design of future products and enable the integration of product and service offerings through the paradigm of "shift of ownership" (e.g., Tukker and Tischner, 2006).

\section{THEORETICAL FRAMEWORK FOR SUSTAINABLE PRODUCT DEVELOPMENT IN MAKERSPACES}

Previous studied literature showed primarily experience-based reports, but little actual research on makers' practice and impact had been conducted so far. Considering the highly diverse motivation and knowledge base for using the physical (e.g., spaces, machines) and virtual artifacts (e.g., collaboration and communication platforms) of makers' practice, the following questions can be identified in the context of promoting sustainable development practices: (I) How can knowledge about the development of sustainable products be integrated into makerspaces in such a way that users are motivated to learn more 


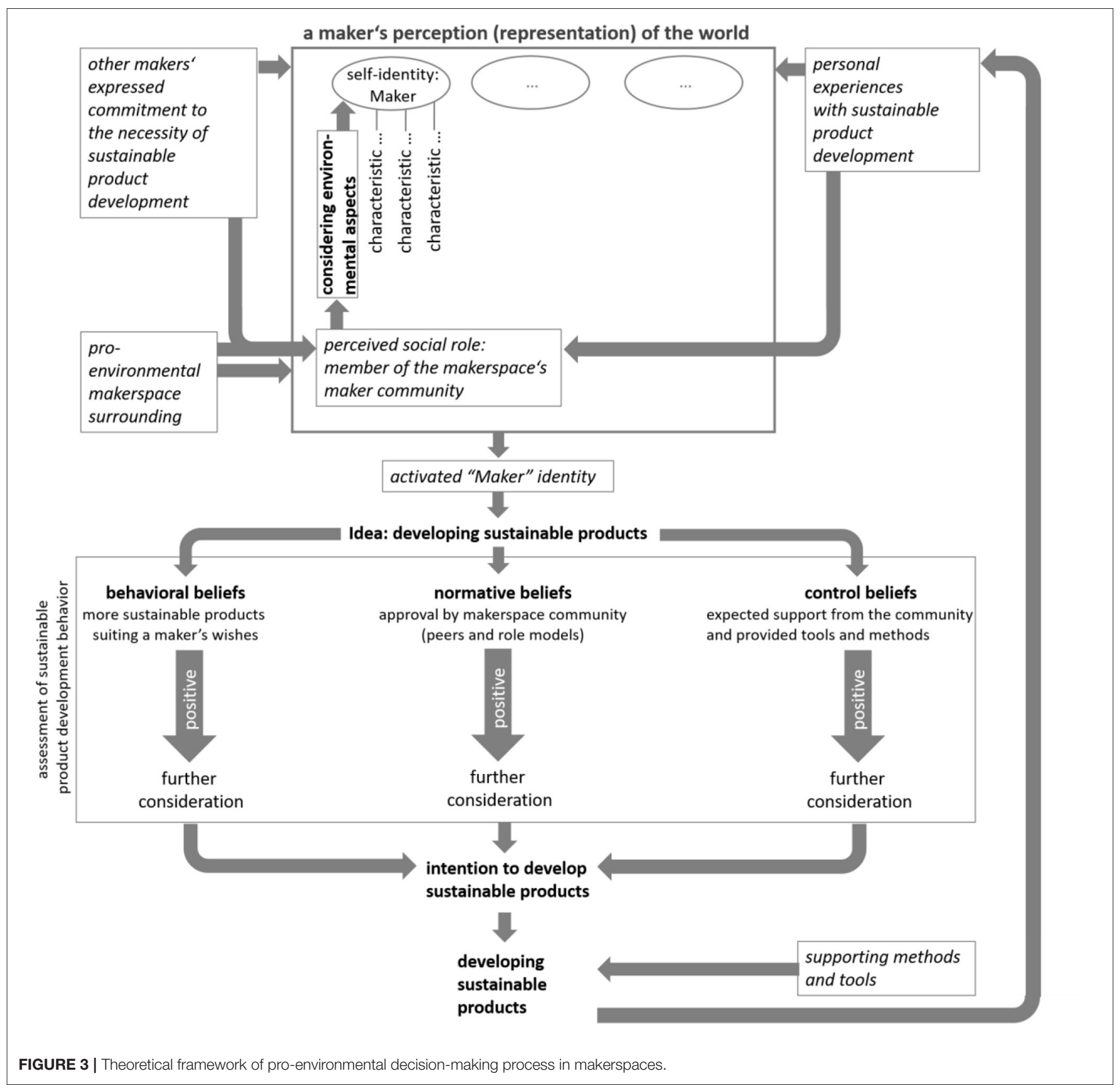

about these approaches independently or to apply this knowledge in their own development projects? (II) How can makerspaces be increasingly used as hands-on experimental environments for educating learners in formal educational processes to increase the general interest in sustainability impacts in the context of technology?

Recognizing the above introduced social and environmental psychological approaches to human decision making processes we followed the hypothesis: H1: Sustainable product development in makerspaces can be promoted by adding environmental considerations to the image of the prototypical maker following the Reasoned Action Approach; and $\mathrm{H} 2$ : Transferring environmental considerations to the image of the prototypical maker can be achieved by creating a surrounding in which sustainable product development is omnipresent and thus reflects the makerspace's commitment to sustainable product development and primes the perception of the makers for sustainability.

Applying the theoretical basics of decision making to promoting sustainable product development in makerspaces leads to the theoretical framework of pro-environmental decision making in makerspaces as shown in Figure 3. By creating 


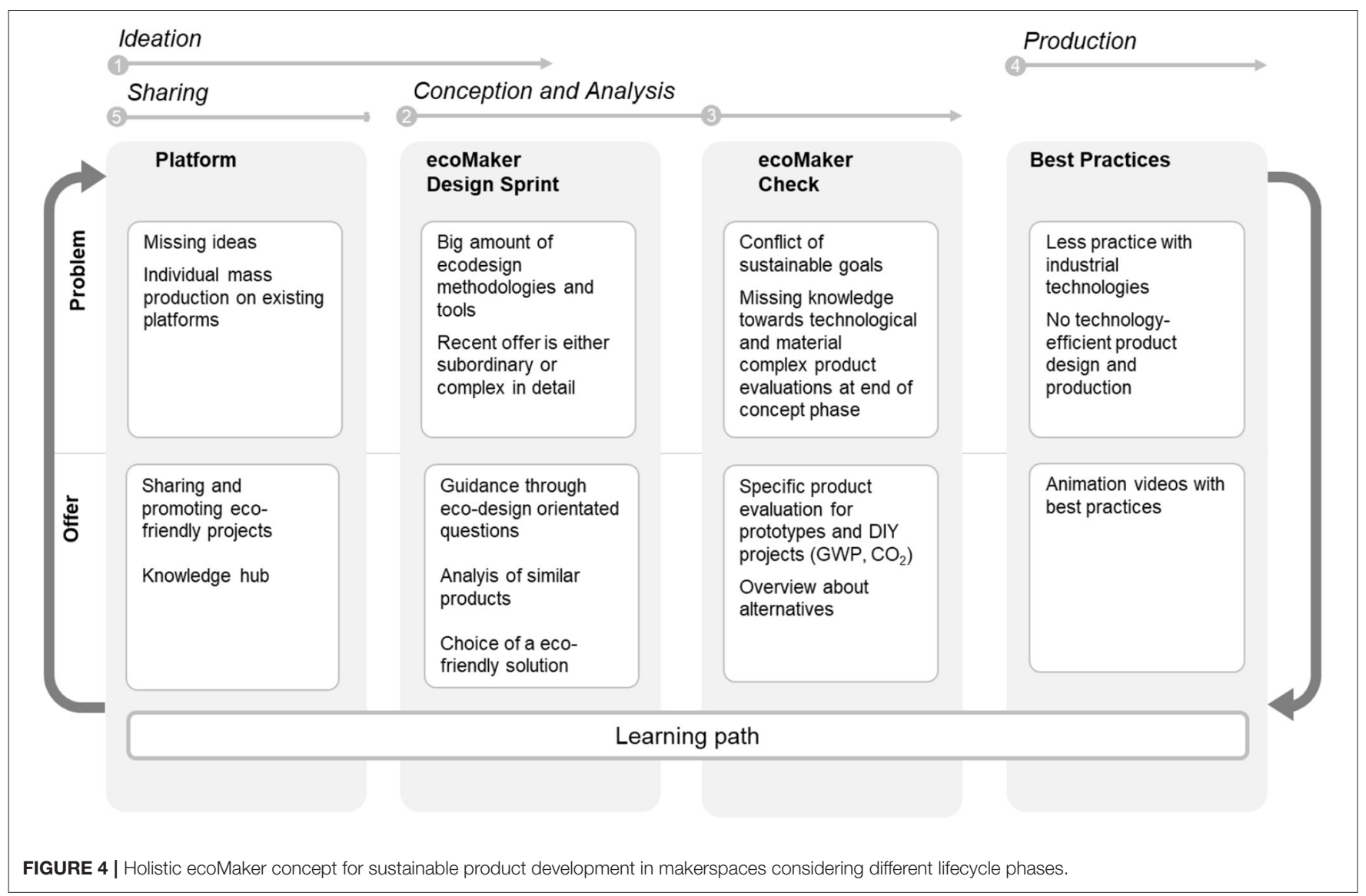

pro-environmental makerspace surroundings together with the makerspace's operators, the perceived social role of the maker as part of the makerspace's community is shifted toward being part of a community that identifies with environmental aspects of its daily practice. This social role triggers the makers to choose such characteristics of their self-identity as being dominant that go well with the perceived slightly shifted role. Since other community members also undergo the same process, they animate each other further by exhibiting commitment to the necessity of sustainable product creation and thus strengthening the collective perception of sustainable product development as integral part of maker identity. With this shifted maker identity at work community members who identify themselves as makers consider acting accordingly by developing more sustainable products. The intention is formed by assessing behavioral, normative and control believes which come to an overall positive conclusion thanks to the favorable perspective on the topic within the community and the pro-environmental makerspace surroundings that include supporting methods and tools for sustainable product development. It is also due to those supporting structures that the intention can be turned into action successfully. This personal experience will then gain help to further strengthen the maker's perception of himself, making and the prototype of a maker as being connected to sustainable product development. This is of course just a schematic view on the complex processes that take place within people and social groups but they are capable of providing orientation when making an effort to shift every day practices within makerspaces toward environmental sustainability.

\section{FROM THEORY TO PRACTICE: CONCEPT DEVELOPMENT}

Before starting developing things one must know one's target group. A literature review had been fruitless regarding detailed information on makerspace user's attitudes, working modes and so on for the German context. Therefore, the diverse users of makerspaces rough user groups were defined and an individual survey design was developed depending on access to each group. First, a cross-sectional study-an online questionnaire for 47 German makerspaces-was conducted, mainly supported by the community of FabLab Berlin [for more detail see Klemichen and Roeder (2018)]. The participants were surveyed on attitudes, routines and needs as a door opener for the development of assisting tools. Another item set clustered around makers' understanding of sustainability. This was additional reinforced by the requested demonstration of their last considered key aspects of sustainability in their own projects as well as their experience with methods and tools that they had used. Moreover, the online survey was appended by qualitative guideline interviews with five start-ups situated at Fab Lab Berlin and workshops held with 
actors from the educational landscape-university students, pupils and teachers at different qualification levels.

It became clear that while in all user groups awareness for the need for environmentally sustainable development existed, the maker's own potential contribution was considered too small to be worth the effort. Therefore, lack of knowledge regarding tools and methods or materials and processes as suggested by Unterfrauner et al. (2019) is only part of the explanation of the attitude-behavior-gap. Even more important it seems is the basic attitude of makers during their work in the makerspace, in which sustainability factors often take a back seat. In the view of many makers, these factors play a subordinate role for their maker identity. This corresponds with Toombs et al. (2015) who identified market independence, individualism and openness for mutual support as major aspects of maker' selfidentity. Therefore, simply providing tools and methods does not lead to more ecofriendly behavior in makerspaces as long as ecological sustainability is not an integral part of makers' selfimage or community norms. In order for tools and methods to have a chance of acceptance, the image of the maker must first be opened up to the concept of ecological sustainability.

\section{A Two-Stage Approach to Connect the Image of Makers to Sustainable Product Development}

There are several principles around environmental issues leading to a shifting mindset (Berglund and Kohtala, 2020). These are closely related to the maturity of knowledge due to tools, technologies, and techniques arising by themselves through creativity and experience processes. These practices represent the prime asset of the maker community, further strengthened by peer support. We believe that an expanded range of methods and tools with a special focus on ecological design combined with resource-efficient production can favorably affect individual performance. However, as discussed above methods and tools only might have such an impact on makers' practices when community norms and maker identity have already experienced a shift toward sustainable product development. Availability of tools by itself does not shift mindsets. Nevertheless, they are essential to support this shift when makers are tentatively starting to check their capability of developing products more environmentally friendly. To put it in Fishbein and Ajzen's (Fishbein and Ajzen, 2010) words, even when makers' expect sustainable product development to have positive effects (behavioral beliefs) and apply to their community's norms (normative beliefs), they will still consider their expectations regarding barriers and facilitators before engaging in sustainable product development (control beliefs). Those expectations will also be formed by the availability of facilitating methods or tools.

The ecoMaker concept therefore follows a two-stage approach. In the first step, sustainable product development has to be put on the agenda in makerspaces and their communities in order to increase the association of maker surroundings and sustainable product development. A commitment to sustainability needs to become physically visible in the makerspace. This does not have to be done by means of some makerspace charter being pinned to the wall but can happen more subtle and thus more convincing e.g., by integrating sustainability tools into the tool kit provided by the makerspace, establishing a storage of leftover materials for free use, offering environmentally friendly materials and marking them as such, marking bins for separating waste and include sustainable product development into existing workshop series. Such actions represent commitment by the makerspaces' operators who are also role models within the makerspace's community and therefore have a strong impact on the community's norms. In the second step, it has to be made easy for those makers who, as early adopters within the communities, begin to look for opportunities for ecofriendly product design to also find those opportunities easily to allow for a feeling of control and keep them on track.

However, in practice there were synergies between those methodologically separated steps within the ecoMaker project. An important component in changing makers' practice, it has been argued, is to influence the image of makers was to change the image of the makerspace as a physical and social environment for action and a place of identification for makers. Visible omnipresent symbols for a commitment of the makerspace to its responsibility for environmental sustainability served as the basis for this. Yet, the very tools and methods that were developed to provide the early adopters with easy access to knowledge and techniques in the second step were developed and designed to also serve as these same symbols by being presented and offered at various places within the makerspace in the first step.

\section{BECOMING PRACTICAL: IMPLEMENTATION OF THE ECOMAKER CONCEPT}

A number of different solutions for environmentally friendly product development was developed that can be easily installed in makerspaces to promote its sustainability commitment while at the same time facilitating environmentally friendly practices. Since the two partner makerspaces (FabLab Berlin and VINN:Lab Wildau) were already following basic measures of environmental protection (separating waste and collecting scrap materials) as is usually the case in Germany, we concentrated on concrete challenges of environmentally friendly product development.

Since we wanted early adopters to find assistance for their projects for whatever design phase they were going through at that time, we decided to develop solutions for all design phases from the project idea through conceptualization, evaluation and finally to dissemination within the network (see Figure 4). The solutions are based on approaches from engineering practice (e.g., simplified life cycle assessment, design for $\mathrm{x}$ ), combined with established methods from the start-up scene (e.g., design thinking) as described above in the framework for sustainable product development. They are freely available on the project's website, following an open-source approach. The ecoMaker methods and tools set includes an online knowledge sharing platform, the ecoMaker Design Sprint, the ecoMaker Check, best practice animations, and a learning path concept all targeting environmentally friendly product development specifically in makerspaces. 


\section{Platform for Inspiration and Sharing Ideas}

Platforms offer a space for users to implement their own projects, to learn new things, but also to pass on knowledge gained during project implementation (Voigt et al., 2018). The open and collaborative exchange also allows for iterative evolution, as each participant develops a design according to his or her needs. This creates a process of learning from each other and learning by doing. The learning process thus has a primarily informal character. Existing platforms such as instructables.com already provide makers with an option for making knowledge available, but offer such an abundance of projects and project ideas (Voigt et al., 2018) that it is difficult to filter environmentally friendly or environmentally designed projects. However, the facilitated access to technologies equally results in rebound effects in the form of increased production of individual products. The fostering of an open community for specifically environmentally friendly product design is thus one of the unique selling points of the developed platform, along with the additional offer of the knowledge hub whose focus has emerged through the previous survey (Klemichen and Roeder, 2018). The platform is composed of the following core elements: (1) The project gallery offers a platform for presenting one's own finished projects and the opportunity to receive feedback as well as suggestions and recognition from the community. The benchmark is either the use of environmentally friendly materials, environmentally friendly production and the reference for a sustainable everyday life; (2) Detailed documentation of the projects is presented in the replicas' section, where the maker can share step-bystep descriptions of project implementation, tools and materials used, and lessons learned with the community. The instructions can be made understandable by embedding images, videos and PDF documents (see Figure 5); (3) In addition to learning about applied project practice, knowledge along the product development process will be provided in the knowledge hub. The content is strongly oriented toward the needs and the level of knowledge of the Maker community. Due to the strong diversity of possible maker projects, an universal knowledge space was created that provides links to existing knowledge for a wide variety of topics as a primary support measure for the community, which is flooded with information and tools. For this reason, several questions were integrated into the knowledge representation such as basic approaches (Circular Economy, Peer-To-Peer Production), checklists, methods for product creation, software, and expert systems that are based on systematic literature research as well as on interviews regarding applied practice within the maker community itself. The selection of content was made using criteria for instance number of sustainability aspects covered, general effort, life cycle phases, availability, time required. Through the aspect of sharing project ideas promoted by providing concrete instructions, the makers should not only be encouraged to be inspired by sustainable ideas, but equally proud to present and further develop their own ideas.

\section{ecoMaker Design Sprint}

Design sprints are a method that originate from design thinking approaches. They describe a development process usually split in the five phases (1) understand, (2) diverge, (3) converge, (4)

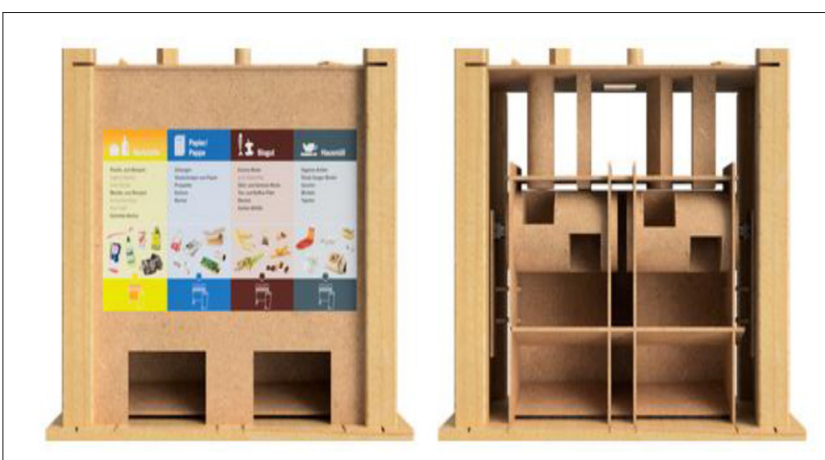

FIGURE 5 | Replication of a the learning tool "Garbage Separation Bot"” developed within a student project.

prototype, and (5) test (Knapp et al., 2016). The method has been developed to bring innovative products to market and reduce market risks by including a very broad system level perspective into the product development. The ecoMaker Design Sprint takes an entry-level perspective on environmentally friendly product design (Roeder and Klemichen, 2019). The systems thinking approach as a whole seemed too ambitious for participants who have little prior knowledge of both sustainability and market economics. Therefore, the design sprint format was adapted to focus only on product design, excluding any broad market considerations and testing phases, and thus helping makers to thoroughly challenge their project ideas regarding environmental sustainability. This process has been structured by three sub sprints: Basic Sprint, Eco Sprint, and Idea Sprint. The ecoMaker Design Sprint can be integrated in e.g., a hackathon format to reach the state of physical prototypes (see Figure 6).

The "understand" phase of typical design sprints is represented by the Basic Sprint during which participants undertake a product tear-down (Otto and Wood, 1998), meaning they define all parts and functions of their targeted product for better understanding the product. The "diverge" phase is represented by the Eco Sprint and concentrates on identifying eco-friendly alternatives for each defined part and function to open up the solution space. This space is then narrowed down in the "converge" phase, represented by the Idea Sprint. This is when participants choose a number of identified alternatives which they actually want to integrate into their product. This narrowing down of the solution space is equivalent to the cognitive process that has been described as strategic control or synthesis in design thinking (Kolodner and Wills, 1996; Razzouk and Shute, 2012). The modeling and production phases were not considered part of the design sprint, so that the "prototype" and "test" phases were excluded from the design sprint.

In order to integrate environmentally friendly product development into maker community norms, the means of its application could not conflict with existing norms. The ecoMaker Design Sprint's concept therefore comes with additional tools that ensure that the makers can perform the design sprint mostly on their own, without a guide. This takes into account 

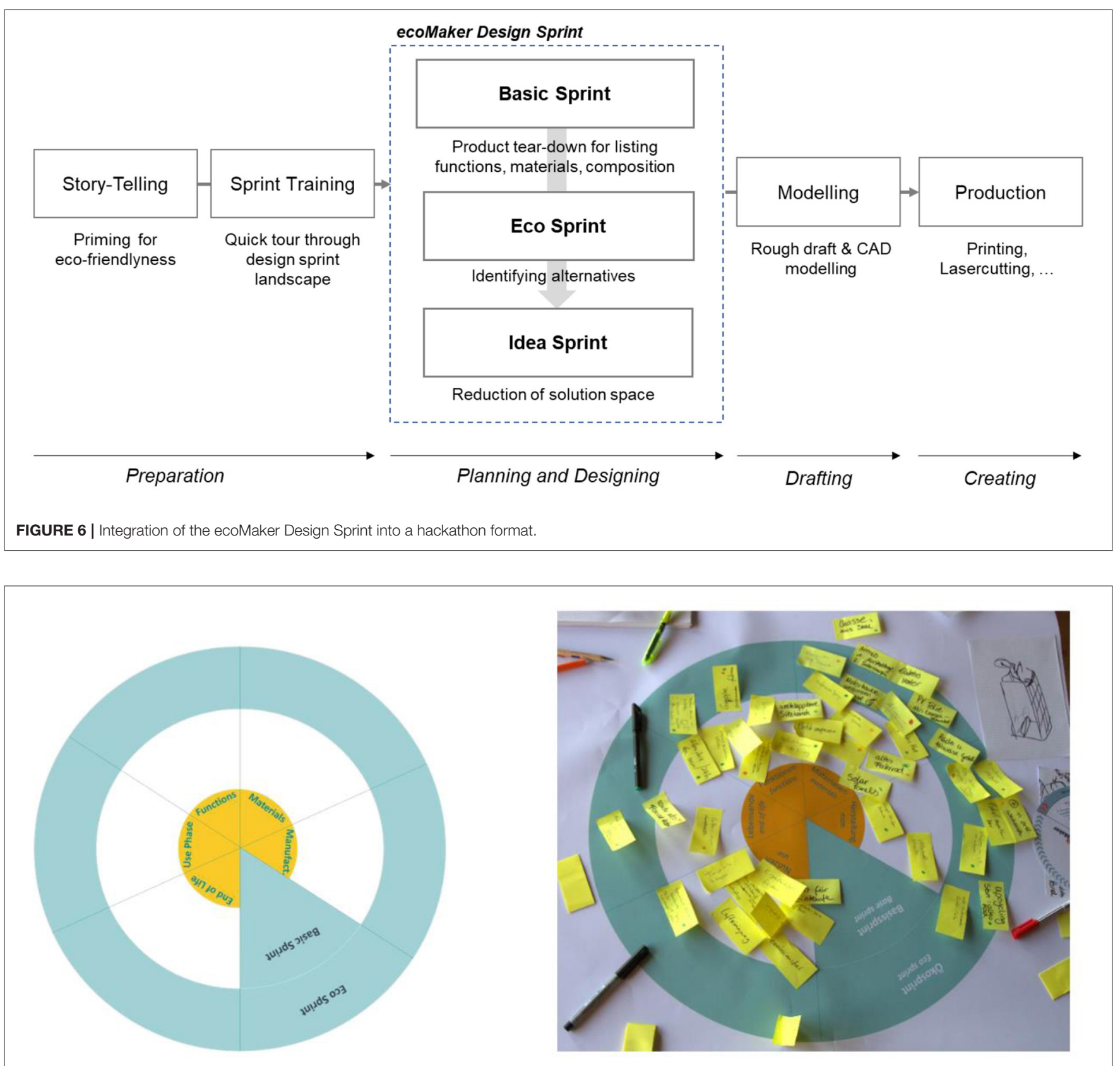

FIGURE 7 | ecoMaker design sprint canvas.

the desired independence of makers, which not only emerges from the cited scientific literature, but was also evident in the method' testing iterations. The principal tool is the canvas, which represents two concentric circles to provide visually separated areas to work in during the Basic Sprint and the Eco Sprint (see Figure 7). In the center, a third circle segments the sprints according to the impact fields of manufacturing, materials, function, end of life, and use phase, which allows makers to think through the wide variety of possible impacts of the project idea in a structured way within more manageable domains. To make makers familiar with the sheer number of aspects that could be considered during the Eco Sprint, when it comes to finding more eco-friendly adaptations of the original project idea, a cardboard-based tool with guide questions is offered in a wheel design. Underneath the three key fields that identify possible eco-friendly improvements, namely materials, processes, and end-of-life, the maker is presented guiding questions, such as "Where do the raw materials come from?" or "How can energy be conserved in this process?" To support the subsequent reduction of the solution space by dismissing inappropriate 


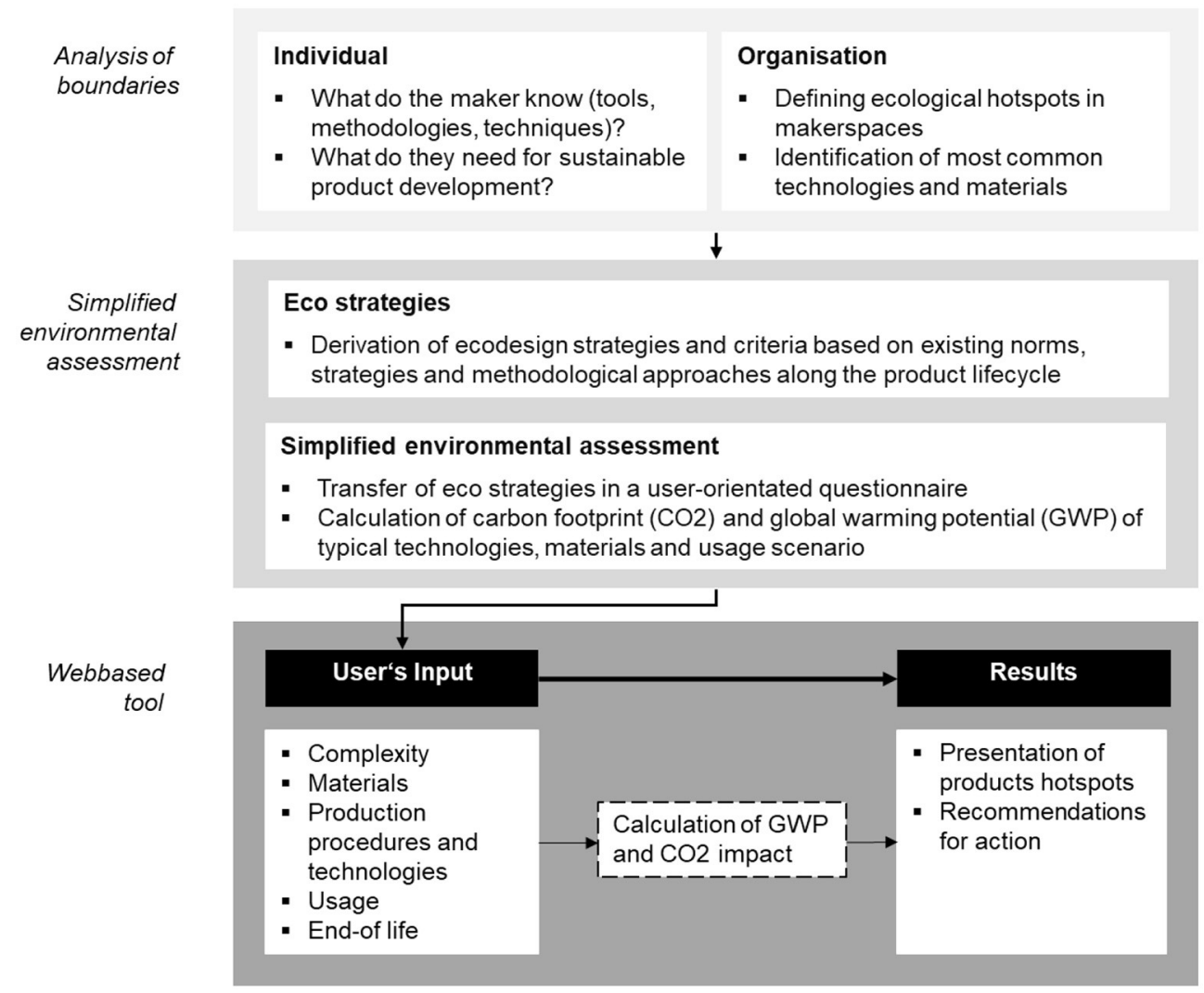

FIGURE 8 | Principles behind the ecoMaker check.

solutions during the Idea Sprint, makers are offered a logbook. It contains the most frequently mentioned exclusion criteria from the initial survey, that are accessibility, time and cost. It also offers space for further personal demands such as aesthetics, again, in order to offer the greatest possible scope for the independence of the makers and thus to emphasize that they are the ones who shape the process. Also within the predefined categories of accessability, time and cost, the makers are requested to set their own tolerance limits for the evaluation system.

\section{Simplified Life Cycle Analysis for Prototypes-ecoMaker Check}

The analysis assistant ecoMaker Check shall support makers more concretely in the selection of processes and materials as part of their product development process. The configured product is also to be evaluated. Thus, transparency for the own product is to be created regarding the improvement potentials of the product. The assistant fulfills the following tasks: (1) Support in the selection of design strategies, (2) Overview of the sustainability issues that affect a product (3) detailed information about the advantages and disadvantages of individual selection variants and finally (4) evaluation of the product in terms of ecological design strategies and visualization of the global warming potential and the CO2 footprint (see Figure 8).
This was followed by the research phase on existing legislation and political strategies (e.g., Circular Economy Action Plan, UNEP Report Design for Sustainability). Due to the fact that ecodesign is already an established method in product development a solution had to be found on how to use this knowledge for a simplified product evaluation from an environmental point of view. Therefore, in order to develop an evaluation method for the web-based tool ecoMaker Check, ecological product aspects, and design criteria were elaborated taking into account the characteristics of makers as production environment. Since there was no set of design strategies and criteria that consider environmentally friendly behavior and production methods that could be used to evaluate product development in makerspaces, a general design for sustainability strategies was used.

Thus, a wide range of improvement directions can be covered in all phases of a product's life cycle. A checklist was then used to translate the criteria that characterize the strategies appropriate to the maker's action options into understandable multiple-choice questions. The answers are translated into a numerical scale representing the fulfillment rate of a design strategy and assigned along the life phases of the product. Here, the makers have to go through the whole life cycle of the product starting from complexity, materials, manufacturing, using, repairing as well as disposal. By means of info boxes 
that accompany the Makers during the run and can be clicked on, additional inspirations regarding alternative materials, production techniques or options for action are to be created. The answers are used to determine the extent to which the product meets the defined ecodesign criteria. Since each criterion was previously assigned a value on a numerical scale, these values can be summarized so that a more comprehensive statement can be made about the extent to which a product fulfills the ecoMaker strategies in each life cycle phase. A simplified calculation of the product's carbon footprint can be performed at the same time using the questions and answers in the ecoMaker Check. Here, the greenhouse gas emissions during material manufacturing, production and disposal are considered and was carried out using the Gabi 6.0 software. This impact assessment was carried out using the CML2001 methodology for life cycle assessment.

\section{Best Practice Animations and Learning Path}

Together with our partner makerspace, the ViNN:Lab, typical errors (regarding e.g., design, machine operation, material selection) that lead to production errors and material waste were identified for each individual station in the makerspace, for which instructions for makers could be formulated in a second step. This was done in the form of short animations that can be either used for trainings or called up via a $\mathrm{QR}$ code on personal devices to implement a learning path through the physical makerspace. For this the codes that lead to the animations are placed throughout the makerspace to match the respective workstation, starting at the entrance to the lab with references to online platforms for inspiration for sustainable project ideas, through the exhibition area, where example products are referred to, e.g., to show the influence of the printing direction in the $3 \mathrm{D}$ printing process on the surface structure of the printed object, toward the material store with suggestions on the appropriate choice of material, the computer workstation with useful design clues, and finally the machine tools with operating instructions. The concept provides learning paths in the form of footprints sticked to the ground that guide makers through the appropriate content along their intended production method. Of course, in an ideal case the learning path would also refer to the other tools and methods from the ecoMaker project that would have been implemented in the makerspace beforehand. The platform would be referred to right in the entrance area or at a showcase of products realized in the makerspace, since this is where inspiration for environmentally friendly projects could be found. The ecoMaker Design Sprint would be integrated around co-working areas and the ecoMaker Check at computer work stations. In this second option of using the best practice animations to create a learning path the knowledge transfer is merely a positive side effect of the primary purpose to make commitment for environmentally friendly product development visible in each and every corner of the makerspace to influence both community norms and consequently the self-identity of makers as well as the control beliefs of makers when it comes to the decision of actually acting in environmentally friendly ways when making.

\section{EVALUATION OF TOOLS AND METHODS}

\section{Limitations}

The survey, interviews and workshops that formed the basis for the ecoMaker concept were all limited to the German context. Furthermore, the development and evaluation design had to be adapted for each tool and method of the concept, due to the diversity of the targeted users and the specifics of the Makers' work culture, which, for example, clearly favors informal dialogue over more formal methods. Therefore, a set of individual strategies had to be developed, rather than an easily replicable single method that would have allowed for greater comparability. The most serious limitation, however, was the closure of the project's partner makerspaces due to the Covid 19 pandemic regulation in the middle of the final evaluation of the overall approach. Thus, while the individual methods and tools have been tested and their usefulness and functionality ensured for step two of the ecoMaker approach (providing helpful guidance to early adopters), the subsequent step (adding sustainable product development to the maker image through the widespread use of various tools and methods within the makerspace) needs to be evaluated.

\section{Sharing Platform}

First, the platform concept was tested at an early stage with an initial functional mock-up in an internal expert workshop with scientists from the context of virtual product development and sustainable engineering. For this purpose, various personas were defined to imitate different makers' background such as age, professional activity, technical and ecological prior knowledge, maturity level of product idea. Those were assigned to the participants. The knowledge hub received particular attention of the participants. In some cases, more in-depth information on specific topics was desired (for e.g., assistance on sustainable production and individual principles of the circular economy). At the same time, the information should be presented briefly and precisely. Secondly, students should document and publish their projects on the platform in accordance with the open source paradigm as part of a students' project to develop environmentally conscious inter-generational games. From them we received feedback that there was still some potential for improvement in terms of usability, which was subsequently realized.

\section{ecoMaker Design Sprint}

The ecoMaker Design Sprint was expanded in several stages, tested at maker specific events, and constantly improved. In the first development phase, the approach was tested during two hackathons lasting several days at the partner fab lab in cooperation with a vocational school and a high school. In the first session, the students were supported with cards on sustainability indicators in the ecoSprint. Since these tended to confuse rather than support, they were replaced in the second implementation by the cardboard wheel with guiding questions 
along which the students could identify sustainability factors for their product sessions with a total of 12 participants. The event was used to further develop the design sprint to test it with other target groups. For this purpose, the tools (canvas and wheel) were revised. Furthermore, a MET-Matrix (material, energy and toxic emissions) enabling a qualitative assessment of product life cycle, was provided for the identification of ecological weak spots of the product ideas. The workshop resulted in positive feedback from the participants on the design sprint and clearly showed that the sprint and the associated tools were quite helpful with basic knowledge of the ecoDesign topic. However, the MET matrix was rarely used, all teams preferred the wheel with guiding questions along the product life phases. Within the framework of a large multi-day public hackathon, the design sprint was implemented into a wider design thinking hackathon format in collaboration with the learning factory ecoDesign. The participants of the four teams went through a very tightly scheduled workshop, in which first business concepts and finally associated products and services were to be derived from a predefined futuristic mobility scenario. Although all participants were able to finally prototype and demonstrate their ideas (e.g., flexible scooter helmet, hitchhiking app, flexible convertible, and renewable energy powered gondola), participants complained about the tight schedule that required teams to make quick decisions. This restricted the concepts, some of which had not yet been finally evaluated in the group discussion, from being thought through in the best possible way. The ecoMaker Design Sprint, however, received excellent feedback for being useful while granting the makers full autonomy. Thus, the goal for was reached both in terms of having a positive practical impact and meeting acceptance.

\section{ecoMaker Check}

The development of the analysis assistant ecoMaker Check also followed an iterative work process. According to the survey users preferred a supporting tool for comparing different product scenarios as well as an environmental life cycle assessment. The early concept evaluation was performed using a clickable mockup with five makers, which was tested in a partner makerspace ViNN:Lab. For the evaluation, participants were asked to imagine either their own project or a given one and then run through the assistant. The survey then focused on usability and the logical process. The majority found the tool easy to use and agreed that it was easy to learn without external help or a manual. Furthermore, it was well-customized to the requirements of the work. With regard to the statement of unnecessary entries and the constraint of needless work steps, the participants expressed moderate satisfaction. The questions were understandable in a standard manner and could partly help to obtain a new perspective on product development or to better understand one's own product. Moreover, the participants requested additional information boxes, for example on specific material properties and production possibilities as well as the effects of the decision parameters on the overall ecological impact of the product or prototype. After the final implementation of the assistant, a test scenario (design of a lemon squeezer) was created for the final evaluation. The participants had to use the example to design a first concept with first strategies along the product life cycle without the assistant. Then they were supposed to run through the assistant with the developed concept. The evaluation was attended by 13 makers with different levels of knowledge about sustainable product development, materials and production techniques and in compliance with selected criteria of ISO/IEC 9126 (effectiveness, efficiency, satisfaction). On average, the tool performed reasonably well in the area of effectiveness. The provided information helped to better assess environmental impacts and participants indicated that the tool supported them to gain knowledge about sustainability in the development process. In contrast, conflicting goals could rarely be identified. Six participants felt that the tool had a positive impact on the environmental performance of the product. There were four participants who stated that the tool would only partially affect them, and three participants stated that there would be no impact. Regarding the efficiency of the tool, testers we generally satisfied regarding time required, comprehensibility, and logical operation. There was a high agreement that the tool could be well-integrated into the everyday life of makers, which, unfortunately, does not correspond to their own statement regarding their own intent to use the tool regularly in the future.

\section{CONCLUSION}

Makerspaces are not as environmentally-oriented as often proclaimed in literature and media. However, certain maker groups do have high potential of being activated as sustainability advocates by psychological processes making use of concepts such as self-identity, priming and Reasoned Action Approach, especially promising when focusing on normative beliefs (influencing norms in the community through the makerspaces position and omnipresent visibility of the topic) and control beliefs in terms by offering physical and digital tools and methods and making commitment visible. Thus, in the ecoMaker project we set out to try to merge social psychological and engineering knowledge from product development to develop useful methods and tools-to be visibly presented in the makerspace-to foster a higher active awareness of environmental sustainability with the aim of promoting sustainable action within the community. Thus, makerspaces themselves operate as a local service not only for technology sharing but also as an enabler for promoting a paradigm shift from "make it fast and cheap" to "make it sustainable." Especially, those who could be encouraged to take on the role of early adopters of techniques for environmentally friendly product development should also find easy access to information. For this purpose a number of example methods and tools were developed that can function as both, assistants for sustainable product development and elements of a pro-environmental makerspace surrounding that promotes environmental considerations as part of the maker identity. Since the concept was co-developed with makerspaces, all elements are adoptable by other makerspaces to be integrated into their spatial and social designs.

The main purpose of the tools was to create an omnipresence of sustainability issues in order to influence the community's 
identification with sustainability and thus the mindset or at least the behavior of community members. Evaluation of the isolated tools to draw on so far, particularly in early sustainability assessment, showed a general interest in the tools themselves, but does not yet seem to have penetrated their day-to-day work. Nonetheless, supporting makers with an intrinsic or extrinsic motivation to take on the role of sustainability pioneer in the community by providing knowledge and guiding methods and tools is essential to maintaining motivation. To promote sustainable value creation patterns in decentralized production, further research must focus not only on the development and deployment of individual tools but also on the interaction between the offer of individual and holistic concepts and the users to assess the impact on sustainable action. In this way, values can first be engaged to the individuals in the long term and consequently also transferred to the community. In order to expand the use of the created offer, it must continue to be carried into the makerspaces via social channels and networks, so that on the one hand the tools can benefit from an expanded level of awareness and on the other hand from the optimization potential through the community itself. Furthermore, the evaluation of the overall concept remains the

\section{REFERENCES}

Ajzen, I. (1988). Attitudes, Personality and Behaviour. Milton Keynes: Open University Press.

Anderson, C. (2012). Makers: The New Industrial Revolution. New York, United States: Random House Business Books.

Andrews, D. (2015). The circular economy, design thinking and education for sustainability. Local Econ. 3, 305-315. doi: 10.1177/0269094215578226

Bargh, J. A., Gollwitzer, P. M., and Oettingen, G. (2010). "Motivation," in Handbook of Social Psychology, eds S. Fiske, D. T. Gilbert, G. Lindzay (New York, NY: Wiley), 268-316 doi: 10.1002/9780470561119.socpsy001008

Berglund, E., and Kohtala, C. (2020). Collaborative confusion among DIY makers: ethnography and expertise in creating knowledge for environmental sustainability. Sci. Technol. Stud. 33, 102-119. doi: 10.23987/sts.60812

Bovea, M. D., and Pérez-Belis, V. (2012). A taxonomy of ecodesign tools for integrating environmental requirements into the product design process. J. Clean. Product. 20, 61-71. doi: 10.1016/j.jclepro.2011.07.012

Buhl, A., Schmidt-Keilich, M., Muster, V., Blazejewski, S., Schrader, U., Harrach, C., et al. (2019). Design thinking for sustainability: why and how design thinking can foster sustainability-oriented innovation development. J. Clean. Product. 231, 1248-1257. doi: 10.1016/j.jclepro.2019.05.259

Chen, M.-F. (2016). Extending the theory of planned behavior model to explain people's energy savings and carbon reduction behavioral intentions to mitigate climate change in Taiwane. Moral obligation matters. J. Clean. Product. 112, 1746-1753. doi: 10.1016/j.jclepro.2015.07.043

Chen, M.-F. (2020). The impacts of perceived moral obligation and sustainability self-identity on sustainability development. A theory of planned behavior purchase intention model of sustainability-labeled coffee and the moderating effect of climate change skepticism. Bus. Strat. Environ. 29, 2404-2417. doi: $10.1002 /$ bse. 2510

Fishbein, M. A., and Ajzen, I. (1975). Belief, Attitude, Intention and Behaviour: An Introduction to Theory and Research. Reading, MA.

Fishbein, M. A., and Ajzen, I. (2010). Predicting and Changing Behavior: The Reasoned Action Approach. New York, NY: Psychology Press; Taylor \& Francis Group.

Geissdoerfer, M., Bocken, N. M. P., and Hultink, E. J. (2016). Design thinking to enhance the sustainable business modelling process - a essential next step e.g., in association with the establishment of an exemplary makerspace.

\section{DATA AVAILABILITY STATEMENT}

The original contributions presented in the study are included in the article/supplementary material, further inquiries can be directed to the corresponding author/s.

\section{AUTHOR CONTRIBUTIONS}

AK, IP, and RS contributed to conception and design of the research. AK and IP wrote the sections of the manuscript. AK designed and described the technological driven tools. IP described the social psychosocial perspective and educational tools. All authors contributed to manuscript revision, read, and approved the submitted version.

\section{FUNDING}

The research work within the ecoMaker project was funded by the German Federal Environmental Foundation. workshop based on a value mapping process. J. Clean. Product. 1218-1232. doi: 10.1016/j.jclepro.2016.07.020

Grabher, G., and Ibert, O. (2014). Distance as asset? Knowledge for collaboration in hybrid virtual communities. J. Econ. Geogr. 14, 97-123. doi: 10.1093/jeg/lbt014

Halstenberg, F. A., Lindow, K., and Stark, R. (2019). Leveraging circular economy through a methodology for smart service systems engineering. Sustainability 11:3517. doi: 10.3390/su11133517

Hartmann, F., Mietzner, D., and Zerbe, D. (2016). Die Maker Bewegung als neues soziales Phänomen - Ergebnisse einer qualitativen Inhaltsanalyse ausgewählter Massenmedien. Wildau: TH Wildau

Klemichen, A., and Roeder, I. (2018). Needs and Requirements for Environmentalfriendly Product Development in Makerspaces-A Survey of German Makerspaces. Wien: Going Green Care Innovation.

Knapp, J., Zeratsky, J., and Kowitz, B. (2016). Sprint. How to Solve Big Problems and Test New Ideas in Just Five Days. New York, NY: Simon \& Schuster.

Kohtala, C. (2016). Making Sustainability: How Fab Labs Address Environmental Issues. Helsinki: Aalto ARTS Books.

Kohtala, C., and Sampsa, H. (2015). Anticipated environmental sustainability of personal fabrication. J. Clean. Product. 99, 333-344. doi: 10.1016/j.jclepro.2015.02.093

Kolodner, J., and Wills, L. (1996). Power of observation in creative design. Design Stud. 17, 385-416. doi: 10.1016/S0142-694X(96)00021-X

Liedtka, J. (2015). Perspective: linking design thinking with innovation, outcomes through cognitive bias reduction. J. Product Innovat. Manage. 32, 925-938. doi: 10.1111 /jpim.12163

Luttrop, C., and Lagerstedt, J. (2006). EcoDesign and the ten golden rules: generic advice for merging environmental aspects into product development. J. Clean. Product. 14, 1396-1408. doi: 10.1016/j.jclepro.2005.11.022

Millard, J., Unterfrauner, E., Voigt, C., Katsikis, O. K., and Sorivelle, M. N. (2017). The maker movement in Europe: empirical and practitioner insights into sustainability. EPiC Ser. Comput. 52, 227-242. doi: 10.29007/8lsf

Newlands, G., Lutz, C., and Hoffmann, C. P. (2018). Sharing by proxy: invisible users in the sharing economy. First Monday 23:11. doi: 10.5210/fm.v23i11.8159

Osorio, F., Dupont, L., Camargo, M., and Pe?a, J. I. (2019). "Constellation of innovation laboratories: a scientific outlook," in 2019 IEEE International Conference on Engineering, Technology and Innovation (ICE/ITMC), 1-10. doi: 10.1109/ICE.2019.8792816 
Otto, K., and Wood, K. (1998). “A reverse engineering and redesign methodology for product evolution," in Proceedings of the 1996 ASME Design Theory and Methodology Conference (Irvine, CA). doi: 10.1115/96-DETC/DTM1523

Oyserman, D. (2015). "Identity-Based motivation," in Emerging Trends in the Social and Behavioral Sciences, ed R. Scott and S. Kosslyn (John Wiley \& Sons). Available online at: https://dornsife.usc.edu/assets/sites/782/docs/ oyserman2015ibm.pdf (accessed February 20, 2021).

Petschow, U., Ferdinand, J.-P., Dickel, S., Fläming, H., Steinfeldt, M., and Worobei, A. (2014). "Dezentrale produktion, 3D-Druck und nachhaltigkeit; trajektorien und potenziale innovativer wertschöpfungsmuster zwischen maker bewegung und industrie 4.0," in IÖW 206/14 (Berlin).

Prendeville, S., Hartung, G., Brass,C., Purvis, E., and Hall, E. (2017). Circular Makerspaces: the founder's view. Int. J. Sust. Eng. 10, 272-288. doi: 10.1080/19397038.2017.1317876

Razzouk, R., and Shute, V. (2012). What is design thinking and why is it important? Rev. Educ. Res. 82, 330-348. doi: 10.3102/0034654312457429

Roeder, I., Klemichen, A., and Stark, R. (2019). "Be(com)ing an eco-maker a prestructured self-learning concept for environmentally-friendly product creation in makerspaces," in 4th International Symposium on Academic Makerspaces (New Haven, CT).

Rossi, M., Germani, M., and Zamagni, A. (2016). Review of ecodesign methods and tools. Barriers and strategies for an effective implementation in industrial companies. J. Clean. Product. 129, 361-373. doi: 10.1016/j.jclepro.2016.04.051

Schoneboom, A. (2018). Making Maker Space: an exploration of lively things, urban placemaking and organisation. Ephemera 18, 709-736.

Sheridan, K., Rosenfeld Halverson, E., Litts, B., Brahms, L., Jacobs-Priebe, L., and Owens, T. (2014). Learning in the making: a comparative case study of three makerspaces. Harvard Educ. Rev. 84, 505-531. doi: 10.17763/haer.84.4.brr34733723j648u

Sherwin, C. (2004). Design and sustainability. J. Sust. Product Des. 4, 21-31. doi: 10.1007/s10970-006-0003-x

Snippe, M. H. M., Peters, G. J. P., and Kok, G. (2021). The operationalization of self-identity in reasoned action models: a systematic review of self-identity operationalizations in three decades of research. Health Psychol. Behav. Med. 9, 48-69. doi: 10.1080/21642850.2020.1852086

Stryker, S., and Serpe, R. (1982). "Commitment, Identity Salience, and Role Behavior. Theory and research example," in Personality, Roles, and Social Behavior, ed W. Ickes and E. Knowles (New York, NY: Springer), 199-218 doi: 10.1007/978-1-4613-9469-3_7

Terry, D., Hogg, M., and White, K. (1999). The theory of planned behaviour: selfidentity, social identity and group norms. Br. J. Soc. Psychol. 38 (Pt. 3), 225-244. doi: $10.1348 / 014466699164149$

Toffler, A. (1980). The Third Wave. New York: Morrow.

Toombs, A., Bardzell, Sh., and Bardzell, J. (2015). “The proper care and feeding of hackerspaces: care ethics and cultures of making," in Proceedings of the 33rd
Annual ACM Conference on Human Factors in Computing Systems, 629-638. doi: $10.1145 / 2702123.2702522$

Tukker, A., and Tischner, U. (2006). Product-Services as a research field: past, present and future. Reflections from a Decade of Research, Journal of Cleaner Production, Product Service Systems: reviewing achievements and refining the research agenda. J Clean Product. 14, 1552-1556. doi: 10.1016/j.jclepro.2006.01.022

Turner, J. C., Hogg, M. A., Oakes, P. J., Reicher, S. D., and Wetherell, M. S. (1987). Rediscovering the social group. A Self-Categorization Theory. New York, NY: Basil Blackwell.

Unterfrauner, E., Hofer, M., Pelka, B., and Zirngiebl, M. (2020). A new player for tackling inequalities? Framing the social value and impact of the maker movement. Soc. Inclus. 8, 90-200. doi: 10.17645/si.v8i2.2590

Unterfrauner, E., Shao, J., Hofer, M., and Fabian, D. (2019). The environmental value and impact of the Maker movement - Insights from a cross-case analysis of European maker initiatives. Bus. Strateg. Environ. 28, 1518-1533. doi: $10.1002 /$ bse. 2328

Voigt, C., Mair, S., and Unterfrauner, E. (2018). "Hacking the knowledge of maker communities in support of 21st century education," in Internet Science Conference. INSCI 2018. Lecture Notes in Computer Science 11193, ed S. Budronova (Cham: Springer). doi: 10.1007/978-3-030-01437-7_22

Wicker, A. W. (1969). Attitudes versus actions: the relationship of verbal and overt behavioral responses to attitude objects. J. Soc. Issues 25, 41-78. doi: 10.1111/j.1540-4560.1969.tb00619.x

Zamiri, M., and Camarinha-Matos, M. (2019). Mass collaboration and learning: opportunities, challenges, and influential factors. Appl. Sci. 9:2620. doi: 10.3390/app9132620

Conflict of Interest: The authors declare that the research was conducted in the absence of any commercial or financial relationships that could be construed as a potential conflict of interest.

Publisher's Note: All claims expressed in this article are solely those of the authors and do not necessarily represent those of their affiliated organizations, or those of the publisher, the editors and the reviewers. Any product that may be evaluated in this article, or claim that may be made by its manufacturer, is not guaranteed or endorsed by the publisher.

Copyright (c) 2022 Klemichen, Peters and Stark. This is an open-access article distributed under the terms of the Creative Commons Attribution License (CC BY). The use, distribution or reproduction in other forums is permitted, provided the original author(s) and the copyright owner(s) are credited and that the original publication in this journal is cited, in accordance with accepted academic practice. No use, distribution or reproduction is permitted which does not comply with these terms. 